\title{
A unified productivity-performance approach applied to secondary schools
}

Citation for published version (APA):

Cherchye, L., De Witte, K., \& Perelman, S. (2019). A unified productivity-performance approach applied to secondary schools. Journal of the Operational Research Society, 70(9), 1522-1537. https://doi.org/10.1080/01605682.2018.1489351

Document status and date:

Published: 02/09/2019

DOI:

10.1080/01605682.2018.1489351

Document Version:

Publisher's PDF, also known as Version of record

Document license:

Taverne

Please check the document version of this publication:

- A submitted manuscript is the version of the article upon submission and before peer-review. There can be important differences between the submitted version and the official published version of record.

People interested in the research are advised to contact the author for the final version of the publication, or visit the DOI to the publisher's website.

- The final author version and the galley proof are versions of the publication after peer review.

- The final published version features the final layout of the paper including the volume, issue and page numbers.

Link to publication

\footnotetext{
General rights rights.

- You may freely distribute the URL identifying the publication in the public portal. please follow below link for the End User Agreement:

www.umlib.nl/taverne-license

Take down policy

If you believe that this document breaches copyright please contact us at:

repository@maastrichtuniversity.nl

providing details and we will investigate your claim.
}

Copyright and moral rights for the publications made accessible in the public portal are retained by the authors and/or other copyright owners and it is a condition of accessing publications that users recognise and abide by the legal requirements associated with these

- Users may download and print one copy of any publication from the public portal for the purpose of private study or research.

- You may not further distribute the material or use it for any profit-making activity or commercial gain

If the publication is distributed under the terms of Article $25 \mathrm{fa}$ of the Dutch Copyright Act, indicated by the "Taverne" license above, 


\title{
A unified productivity-performance approach applied to secondary schools
}

\author{
Laurens Cherchye ${ }^{\mathrm{a}}$, Kristof De Witte ${ }^{\mathrm{b}, \mathrm{c}}$ (D) and Sergio Perelman ${ }^{\mathrm{d}}$ \\ a Leuven Economics of Education Research, KU Leuven, Leuven, Belgium; ${ }^{\mathrm{b}}$ Leuven Economics of Education Research, Faculty of \\ Economics and Business, KU Leuven, Leuven, Belgium; 'Top Institute for Evidence Based Education Research, Maastricht \\ University, Maastricht, The Netherlands; ${ }^{\mathrm{d} D e p a r t m e n t}$ of Economics, Université de Liège, Liege, Belgium
}

\begin{abstract}
We introduce a novel diagnostic tool to improve the performance of public services. We propose a method to compute performance/productivity ratios, which can be applied as soon as data on production units' outcomes and resources are available. Assuming outcome improvement as the main objective in a public services context, these ratios have an intuitive interpretation: values below unity indicate that better outcomes can be attained through weaker resource constraints (pointing at scarcity of resources) and, conversely, values above unity indicate that better outcomes can be achieved with the given resources (pointing at unexploited production capacity). We demonstrate the practical usefulness of our methodology through an application to secondary schools, where we account for outlier behaviour and environmental effects by using a robust nonparametric estimation method. Our results indicate that in most cases schools' performance improvement is a matter of unexploited production capacity, while scarcity of resources is a lesser issue.
\end{abstract}

\section{ARTICLE HISTORY}

Received 3 November 2017

Accepted 11 June 2018

\section{KEYWORDS}

Performance; productivity; resource constraints; secondary schools

\section{Introduction}

One of the major difficulties in the provision of public services (e.g., in health, education, utilities, and transportation) is for the principal to identify underperformance and its origin. It is for this reason that benchmark methodologies such as frontier analysis have become popular in the literature on public sector evaluation (Fried, Lovell, \& Schmidt, 2008). Basically, two different approaches have been used in benchmarking applications. The first approach focuses on performance measurement that exclusively evaluates the general outcomes (e.g., population coverage, quality of service provided and inequality issues), without taking into account resource/input constraints. The second approach, which is the most popular one in the applied literature, concentrates on the measurement of productivity, that is, output performance that explicitly incorporates input constraints. ${ }^{1}$

One essential difference between these two approaches relates to whether or not resource constraints are taken into account. We may also argue that both approaches provide a partial analysis, which may thus give incomplete and potentially misleading information. First, performance scores, also known as measures of effectiveness, tell us to which extent targets are fulfilled, but they do not inform us if the service provided is produced at full capacity. Second, productivity scores show whether or not the service is supplied efficiently (by exploiting the available production capacity in an optimal way), but they do not tell us to which extent the general outcome targets are achieved. The main reason behind this incompleteness is data availability. Very often data on outcomes and resources are not observable simultaneously, or they do not match perfectly for the production units under observation (Lefebvre, Perelman, \& Pestieau, 2017; Pestieau, 2009).

Our paper connects to the literature that discusses the intertwining of efficiency and effectiveness (a review is provided in Førsund, 2017). Up to now, most studies consider the case in which the link between outcomes and resources is not directly observable, basically because other factors out of the control of public services affect outcomes. ${ }^{2}$ Therefore, they proceed in a two-step model. In a first step, they compute efficiency at the public service level using outputs and inputs as in a normal production process and, in a second step, effectiveness is computed at a more aggregated level using outcomes as targets and public service outputs as resources.

This paper provides a unifying framework that fills this informational gap between performance and productivity measures. Our main contribution is threefold. First, we show that when data on outcomes and resources are available for a large sample 
of service production units (called Decision Making Units [DMUs] in what follows), both performance and productivity scores are computable by using an appropriate frontier approach. Second, we propose a novel and simple framework to evaluate the importance of resource constraints. As we will demonstrate in the next section, a performance/productivity ratio below unity indicates that better outcomes can be attained by weakening the resource constraints. In other words, scarcity of resources hampers output performance. On the contrary, assuming outcome improvement as the main objective in a public services context, a performance/productivity ratio above unity indicates that better outcomes can be achieved with the same resources. This mainly signals unexploited production capacity rather than scarcity of resources. Third, we apply the suggested approach to a representative sample of secondary schools in the Netherlands, for which we have exceptionally rich data, covering most outcome and input/ resource dimensions, with identical definitions of the variables. As may be expected, our results show a positive but fairly low correlation between outcome performance and productivity (correlation coefficient $=0.556$ ): many schools doing very well in terms of productivity appear to be less good performers while, conversely, many schools of which students attain high exam scores are characterized by low productivity. This application demonstrates the usefulness of our method (in particular, the performance/productivity ratios) for policy guidance.

The remainder of the paper is organized as follows. In Section 2, we present the theoretical measures of productivity and performance. In Section 3, we show that these measures can be operationalized by solving linear programs of the DEA (Data Envelopment Analysis) form. In particular, we use the robust and conditional DEA form which accounts, respectively, for outlying observations and the operational environment. Section 3 also introduces dual representations of the productivity and performance measures, which gives these measures an additional interpretation in terms of "benefit-of-thedoubt" weighting. Section 4 introduces the data of our empirical application to secondary schools in the Netherlands. In this application, we will account for outlier behaviour and environmental effects, which are essentially resources out of schools' control, by using a robust conditional nonparametric (DEA) order- $m$ approach. Section 5 presents our empirical results. These results will indicate that, in most cases, school performance improvement is a matter of unexploited production capacity (technical efficiency), while resource constraints are a lesser issue. Using quantile regressions, we provide evidence on the characteristics of schools with unexploited capacity and schools with resource constraints. A final section concludes.

\section{Productivity, performance, and resource constraints}

We first introduce our theoretical measures of productivity and performance. The basic difference between these two measures pertains to whether or not resource constraints are taken into account when evaluating the possibility to expand outcomes. ${ }^{3}$ We then also introduce a measure that allows us to identify either possible outcome gains when resource constraints are weakened or, alternatively, unexploited production capacity for the resources that are available.

\subsection{Productivity}

We consider Decision Making Units (DMUs) that use an $N$-dimensional resource vector $\mathbf{x} \in \mathbb{R}_{+}^{N}$ to produce an $M$-dimensional outcome vector $\mathbf{y} \in \mathbb{R}_{+}^{M}$. Productivity relates the resources to the outcomes. In what follows, we evaluate the productivity of DMU $E$, which uses the resources $\mathbf{x}_{E}$ to produce the outcomes $\mathbf{y}_{E}$. We want to measure the productivity of DMU $E$ in relative terms (also referred to as technical efficiency), which compares DMU $E^{\prime}$ s productivity to the maximum attainable productivity for the given state of technology. To this end, we consider the production possibility set $P$, which contains all combinations of resources and outcomes that are technically feasible (including $\left(\mathbf{x}_{E}, \mathbf{y}_{E}\right)$ ). Formally,

$$
P=\{(\mathbf{x}, \mathbf{y}) \mid \mathbf{x} \text { can produce } \mathbf{y}\} .
$$

Throughout, we will assume that the production technology satisfies the technical properties that are needed for our following productivity and performance measures to be well-defined. In particular, we assume that it is characterized by constant returnsto-scale, that is, ${ }^{4}$

$$
\text { if }(\mathbf{x}, \mathbf{y}) \in P, \text { then }(\lambda \mathbf{x}, \lambda \mathbf{y}) \in P \text { for } \lambda \geq 0,
$$

free disposability of resources and outcomes, that is, if $(\mathbf{x}, \mathbf{y}) \in P$, then $\left(\mathbf{x}^{\prime}, \mathbf{y}^{\prime}\right) \in P$ for $\mathbf{x}^{\prime} \geq \mathbf{x}$ and $\mathbf{y}^{\prime} \leq \mathbf{y}$,

and convexity, that is,

$$
\begin{gathered}
\text { if }(\mathbf{x}, \mathbf{y}) \in P \text { and }\left(\mathbf{x}^{\prime}, \mathbf{y}^{\prime}\right) \in P \\
\text { then }\left(\lambda \mathbf{x}+(1-\lambda) \mathbf{x}^{\prime}, \lambda \mathbf{y}+(1-\lambda) \mathbf{y}^{\prime}\right) \in P \text { for } 1 \geq \lambda \geq 0
\end{gathered}
$$

In practice, we typically do not observe the true production set $P$. Empirical production analysis starts from an observed set of $T$ DMUs, with 
resource vector $\mathbf{x}_{t}$ and outcome vector $\mathbf{y}_{t}$ for every DMU $t \in\{1, \ldots, T\}$. This defines the set of observations

$$
X=\left\{\left(\mathbf{x}_{t}, \mathbf{y}_{t}\right) \mid t \in\{1, \ldots, T\} .\right.
$$

The nonparametric approach to production analysis [see, for example, Afriat (1972) and Varian (1984)] adopts the basic assumption

$$
X \subseteq P .
$$

Essentially, this assumes that resources and outcomes are measured without error. Obviously, this is an overly strong hypothesis in many practical situations. Therefore, while we maintain the assumption to simplify our theoretical exposition, we will relax it in our following empirical application (see Section 3.3, where we present the robust estimation method that we will use).

When assuming constant returns-to-scale, free disposability and convexity, we can build the empirical set

$\hat{P}=\left\{(\mathbf{x}, \mathbf{y}) \mid \mathbf{x} \geq \sum_{t=1}^{T} \lambda_{t} \mathbf{x}_{t}, \quad \mathbf{y} \leq \sum_{t=1}^{T} \lambda_{t} \mathbf{y}_{t}, \lambda_{t} \geq 0\right\}$.

It can be shown that this set $\hat{P}$ is the smallest set consistent with our technological assumptions in (1), (2), and (3), and our empirical assumption in (4) [see, for example, Charnes, Cooper, and Rhodes (1978) and Banker, Charnes, and Cooper (1984)]. As such, it provides a useful empirical approximation for the true but unobserved set $P$.

Using this, the relative productivity (or technical efficiency) of DMU $E$ is captured by the degree measure

$$
\operatorname{Prod}_{E}=\min _{\theta \in \mathbb{R}}\left\{\theta \mid\left(\mathbf{x}_{E}, \frac{\mathbf{y}_{E}}{\theta}\right) \in \hat{P}\right\} .
$$

Intuitively, for the possibility set $\hat{P}$, the measure $\operatorname{Prod}_{E}$ captures the maximum (proportional) expansion of the outcome $\mathbf{y}_{E}$ for the given resource $\mathbf{x}_{E}$. Clearly, for an observed DMU $E$ (i.e., $E \in\{1, \ldots, T\}$ and $\left.\left(\mathbf{x}_{E}, \mathbf{y}_{E}\right) \in \hat{P}\right)$ we have $0 \leq \operatorname{Prod}_{E} \leq 1$. Generally, higher values for $\operatorname{Prod}_{E}$ indicate a higher degree of relative productivity (i.e., less possibility to expand outcomes for the given resource). We also say that DMU $E$ is "technically efficient" if $\operatorname{Prod}_{E}=1$.

\subsection{Performance}

Performance evaluation disregards resources and only considers outcomes. Put differently, in terms of our above resource-outcome framework, it implicitly assumes that all DMUs can use the same resources. Performance differences between DMUs are solely defined in terms of outcome differences, because differences in resource/input constraints are ignored.

To formalize this basic difference between productivity and performance measurement, we consider DMUs with constant resources, which we set equal to unity for computational purposes. Following Lovell, Pastor, and Turner (1995), we can interpret this (normalized) resource unit as representing a DMU's apparatus to achieve its outcome goals, a system which we refer to as the DMU's "helmsman" [a concept also used by Koopmans (1951)]. ${ }^{5}$ This system may vary across DMUs, but this variation is viewed as irrelevant for the objective of performance evaluation, which only considers the outcomes achieved and not the size of the underlying resource system.

Using this idea, the relevant set of observations is

$$
X^{\prime}=\left\{\left(1, \mathbf{y}_{t}\right) \mid t \in\{1, \ldots, T\}\right\} .
$$

which has a similar interpretation as the set $X$ used above, except that now each (helmsman) resource is set equal to one. Using the same technology assumptions as before (constant returns-to-scale, free disposability, and convexity), the empirical production set relevant for outcome performance evaluation is given as

$\hat{P}^{\prime}=\left\{(1, \mathbf{y}) \mid 1 \geq \sum_{t=1}^{T} \lambda_{t}, \quad \mathbf{y} \leq \sum_{t=1}^{T} \lambda_{t} \mathbf{y}_{t}, \quad \lambda_{t} \geq 0\right\}$.

Then, the relative performance of DMU $E$ is defined as

$$
\operatorname{Perf}_{E}=\min _{\theta \in \mathbb{R}}\left\{\theta \mid\left(1, \frac{\mathbf{y}_{E}}{\theta}\right) \in \hat{P}^{\prime}\right\},
$$

which looks for the maximum outcome expansion when ignoring differences in resource constraints. Like before, for an observed DMU $E$ we have $0 \leq \operatorname{Perf}_{E} \leq 1$, and higher values for $\operatorname{Perf}_{E}$ indicate a higher degree of relative performance.

\subsection{Resource constraints and unexploited capacity}

We can distinguish three scenarios when comparing the measures $\operatorname{Prod}_{E}$ and $\operatorname{Perf}_{E}$. In the first scenario, we have

$$
\operatorname{Prod}_{E}>\operatorname{Perf}_{E} .
$$

Thus, the maximum outcome expansion without constraints (captured by $\operatorname{Perf}_{E}$, which ignores resource variation) exceeds the maximum outcome expansion with resource constraints (captured by $\operatorname{Prod}_{E}$, which fixes the resource $\mathbf{x}_{E}$ ). This suggests that DMU $E$ can mainly gain in terms of outcome performance by weakening its resource constraints. 
(a) Performance and Productivity

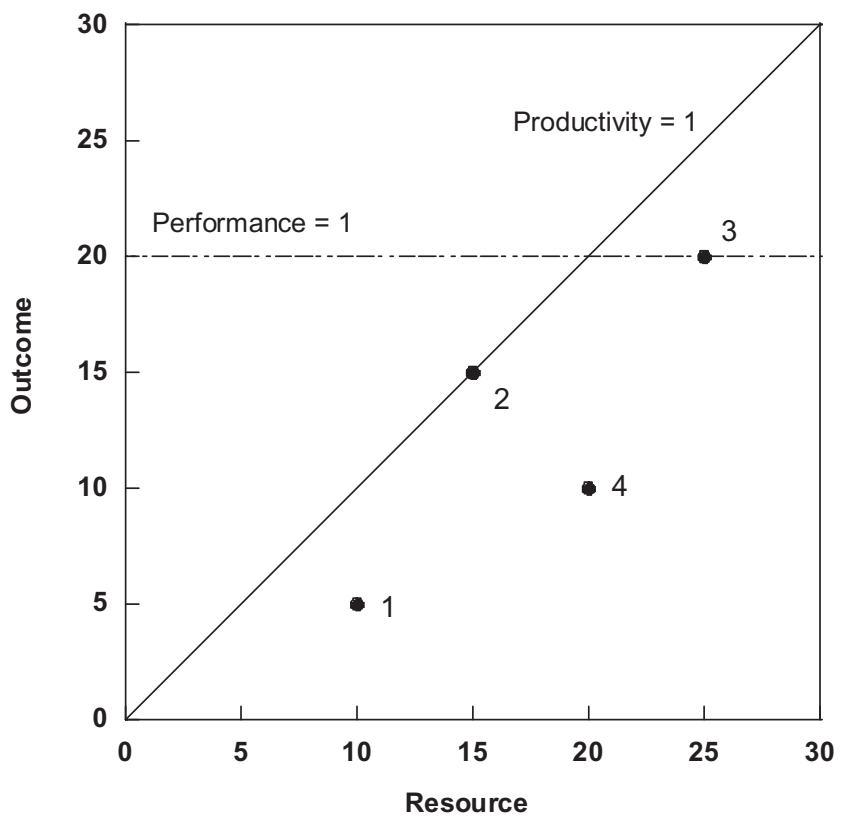

(b) Performance/Productivity

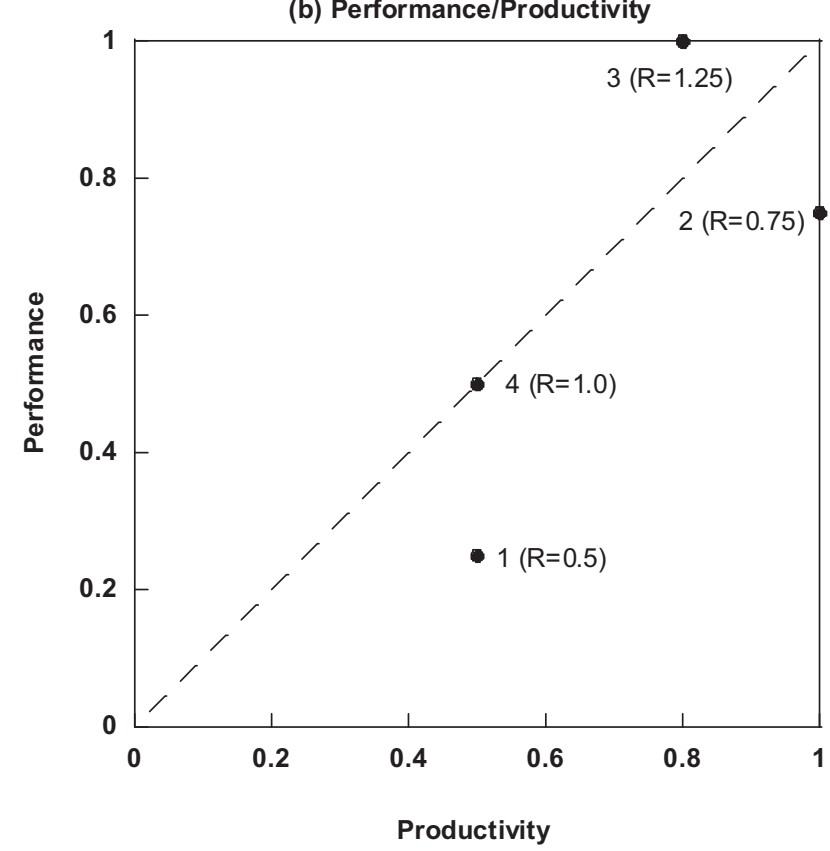

Figure 1. Performance and productivity under constant returns-to-scale.

The opposite scenario occurs if

$$
\operatorname{Prod}_{E}<\operatorname{Perf}_{E} .
$$

This inequality reveals that ignoring the resource variation across DMUs actually improves DMU E's outcome performance. In a sense, the DMU "benefits" when we disregard resource variation, which suggests that the DMU does not fully exploit its production capacity (given the resources that it controls). There is specific potential for outcome expansion even without additional resources.

The final scenario pertains to a situation where

$$
\operatorname{Prod}_{E}=\operatorname{Perf}_{E} \text {. }
$$

Intuitively, the maximum outcome expansion without constraints exactly equals the maximum outcome expansion with resource constraints. In this case, weakening DMU E's resource constraints will not contribute to a better outcome performance, but ignoring the DMU's resource constraints does not improve its production assessment either. Comparing the measures $\operatorname{Prod}_{E}$ and $\operatorname{Perf}_{E}$ does not specifically suggest a particular strategy (i.e., additional resources or better capacity use) to increase outcome performance. Clearly, if $\operatorname{Prod}_{E}=\operatorname{Perf}_{E}=1$, then DMU E is technically efficient and, thus, it can only improve performance by additional resource (i.e., weaker resource constraints) or technical change which shifts the frontier up. However, $\operatorname{Prod}_{E}=\operatorname{Perf}_{E}<1$ reveals that better capacity use can also lead to performance gains (because $\operatorname{Prod}_{E}<1$ ).

Thus, the difference between $\operatorname{Perf}_{E}$ and $\operatorname{Prod}_{E}$ can reveal interesting information regarding specific outcome gains from weakened resource constraints (first scenario) or unexploited production capacity (second scenario). We can distinguish between the different scenarios by using the ratio measure

$$
R_{E}=\frac{\operatorname{Perf}_{E}}{\operatorname{Prod}_{E}} .
$$

The three scenarios discussed above correspond to $R_{E}<1, R_{E}>1$ and $R_{E}=1$, respectively. Greater deviations of $R_{E}$ from unity indicate either more outcome gain to be expected from weaker resource constraints (if $R_{E}<1$ ) or, alternatively, a greater degree of unexploited production capacity or technical inefficiency (if $R_{E}>1$ ). In case $R_{E}=1$, there might still be a problem of unexploited production capacity if $\operatorname{Prod}_{E}=\operatorname{Perf}_{E}<1$.

The following example illustrates the measures $\operatorname{Perf}_{E}, \operatorname{Prod}_{E}$, and $R_{E}$ for a simple setting with only hree DMUs, one resource and one outcome. To better articulate the basic intuition, the three DMUs achieve either $\operatorname{Perf}_{E}=1$ or $\operatorname{Prod}_{E}=1$ (or both). Of course, this intuition carries over to situations with $\operatorname{Perf}_{E}<1$ and $\operatorname{Prod}_{E}<1$. In such situations, $R_{E}<1$ particularly suggests increasing outcome performance by additional resources (i.e., a weaker resource constraints), while $R_{E}>1$ mainly indicates possibilities of outcome expansion by better using the available resources (i.e., improved capacity use).

Example 1. Suppose a set of observations with 4 DMUs $(\mathrm{T}=4)$ that use a single resource $(\mathrm{N}=1)$ to produce a single outcome $(\mathrm{M}=1)$,

$$
X=\{(10,5),(15,15),(25,20),(20,10)\} .
$$


(a) Performance and Productivity

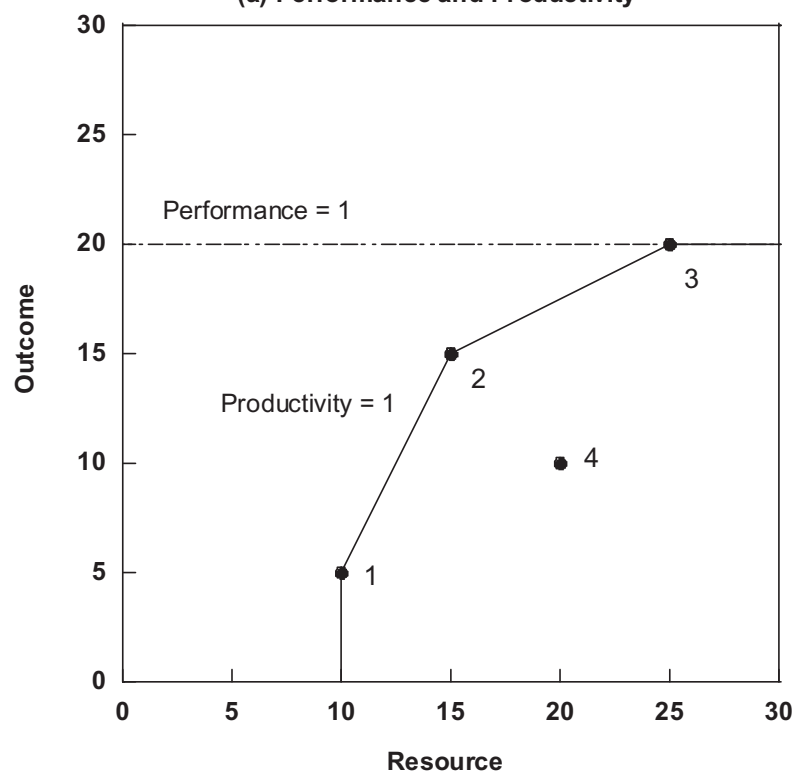

(b) Performance/Productivity

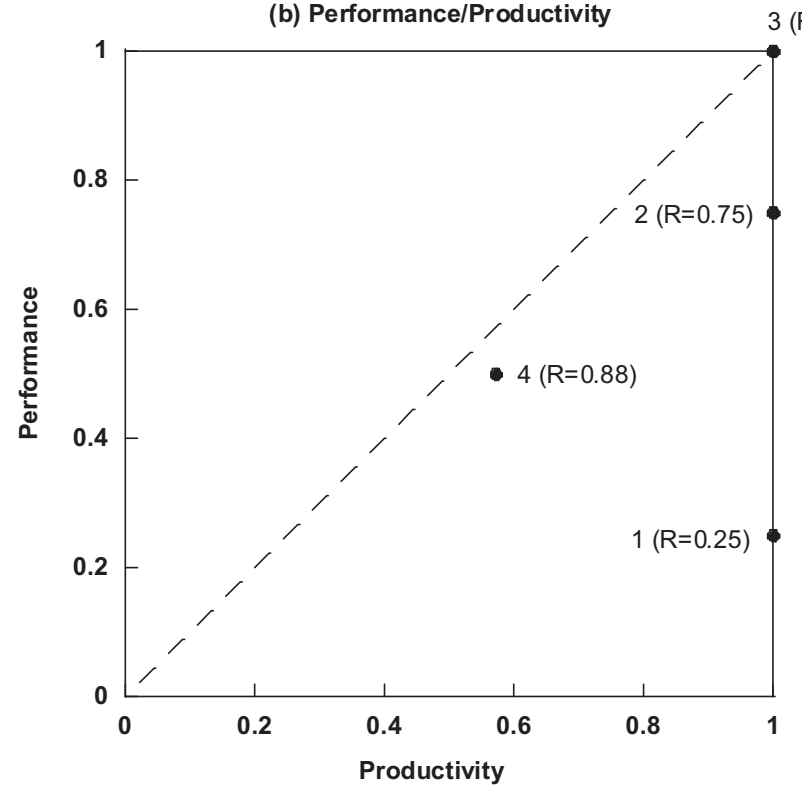

Figure 2. Performance and productivity under variable returns-to-scale.

Correspondingly,

$$
X^{\prime}=\{(1,5),(1,15),(1,20),(1,10)\} .
$$

This gives the results

$\operatorname{Prod}_{1}=0.5, \operatorname{Prod}_{2}=1.0, \operatorname{Prod}_{3}=0.8, \operatorname{Prod}_{4}=0.5$ and

$\operatorname{Perf}_{1}=0.25$, Perf $_{2}=0.75$, Perf $_{3}=1.0$, Perf $_{4}=0.5$.

Given this, we also obtain

$$
R_{1}=0.5, R_{2}=0.75, R_{3}=1.25 \text {, and } R_{4}=1.0 \text {. }
$$

The left panel of Figure 1 shows the DMUs' positions with respect to their performance and productivity benchmarks on the outcome-resource plan (defining $\operatorname{Prod}_{\mathrm{i}}$ and $\operatorname{Perf}_{\mathrm{i}}, i=1,2,3,4$ ), and the right panel of Figure 1 depicts the DMUs' performancel productivity ratios $\left(\mathrm{R}_{\mathrm{i}}, i=1,2,3,4\right)$.

We conclude that DMUs 1 and 2 can mainly improve their outcome performance by increasing their resources (because $\mathrm{R}_{1}, \mathrm{R}_{2}<1$ ). In fact, as DMU 2 is technically efficient (i.e., $\operatorname{Prod}_{2}=1$ ), weakening its resource constraint is the only possibility to achieve a better outcome performance.

By contrast, DMU 3 has potential to improve its outcome performance even without additional resources, by better exploiting its available capacity (because $\mathrm{R}_{3}>1$ ). There is specific potential for outcome expansion even without additional resources. In this particular case, the improvement by DMU 3 corresponds to a performance benchmark that exceeds the best observed performance in our sample; we construct this (virtual) benchmark by exploiting the constant returns-to-scale assumption. Obviously, this benchmark may be unrealistic if DMU 3's performance equals some absolute maximum threshold (for example, referring to our empirical application in Section 4, an absolute maximum possible score on a school exam). In such a case, we may replace the constant returns-to-scale assumption by a variable returns-to-scale assumption, which we briefly illustrate below (see our discussion of Figure 2).

Finally, DMU 4 is in the particular situation of being at the same distance from its performance and productivity benchmarks. As $\operatorname{Prod}_{4}=\operatorname{Perf}_{4}$, the performance/productivity ratio $R_{4}$ does not indicate a specific strategy (i.e., additional resources or better capacity use) to increase the outcome performance. Our data suggest that both strategies are equally productive.

To conclude this example, we illustrate the use of our method under the variable returns-to-scale assumption. This variable returns-to-scale assumption is weaker than the constant returns-to-scale assumption that we have used so far. As indicated above, it may account for maximum thresholds that apply to particular performance dimensions. The left panel of Figure 2 shows the production set under variable returns-to-scale for our example data set. ${ }^{6}$ In this case, we obtain the productivity scores

$\operatorname{Prod}_{1}=1.0, \operatorname{Prod}_{2}=1.0, \operatorname{Prod}_{3}=1.0, \operatorname{Prod}_{4}=0.57$,

As the performance scores remain unchanged, this yields the performance/productivity ratios

$$
R_{1}=0.25, R_{2}=0.75, R_{3}=1.0, \text { and } R_{4}=0.88 .
$$

Figure 2 has the same interpretation as Figure 1 but applies to the variable returns-to-scale case. We learn that the three DMUs 1, 2, and 3 achieve a productivity score of unity, which means that they are technically efficient. When interpreting the associated ratios $\mathrm{R}_{\mathrm{i}}(\mathrm{i}=1,2,3)$, we conclude that there is still room for performance improvement through weaker resource constraints for DMU 1 and - to a 
somewhat lesser extent - for DMU 2. By contrast, when assuming variable returns-to-scale, there is no indication of possible performance improvement for $D M U$ 3: this DMU is technically efficient $\left(\operatorname{Prod}_{3}=1.0\right)$ and achieves the highest possible performance $\left(\operatorname{Perf}_{3}=1.0\right)$, which implies $R_{3}=1$. Finally, we now find that DMU 4 can mainly improve its outcome performance by increasing its resources (because $R_{4}<1$ ).

\section{Operationalization, duality, and robust estimation}

In this section, we show that the measures $\operatorname{Prod}_{E}$ and $\operatorname{Perf}_{E}$ (and, thus, also $R_{E}$ ) can be computed by simple linear programming. This is particularly convenient from a practical point of view. The linear programs are of the form used in the nonparametric approach for production frontier analysis that is known as Data Envelopment Analysis (DEA, after Charnes et al., 1978; see also Fried et al., 2008, for a more recent account of the DEA literature). Attractively, the dual representations of these linear programs also reveal an interesting additional interpretation of our productivity and performance measures. In particular, they show that the measures can be given an intuitive interpretation in terms of "benefit-of-the-doubt" weighting (see also Cherchye, Moesen, Rogge, \& Van Puyenbroeck, 2007). Finally, we will show how we can account for outlier behaviour and environmental effects by using a robust and conditional estimation method that has been proposed in a DEA context.

\subsection{Linear programming formulations}

\subsubsection{Productivity}

As a first step, we note that the constant returns-toscale assumption makes that we can re-write productivity measure (6) as

$$
\operatorname{Prod}_{E}=\min _{\theta \in \mathbb{R}}\left\{\theta \mid\left(\theta \mathbf{x}_{E}, \mathbf{y}_{E}\right) \in \hat{P}\right\},
$$

Using $\hat{P}$ instead of $P$ in this expression defines the empirical estimate $\operatorname{Prod}_{E}$. By combining (5) and (9), we obtain that this measure can be calculated as the outcome of a linear program:

$$
\begin{gathered}
\widehat{\operatorname{Prod}}_{E}=\min \theta \\
\text { s.t. } \theta \mathbf{x}_{\mathrm{E}} \geq \sum_{\mathrm{t}=1}^{\mathrm{T}} \lambda_{\mathrm{t}} \mathbf{x}_{\mathrm{t}}, \\
\mathbf{y}_{E} \leq \sum_{t=1}^{T} \lambda_{t} \mathbf{y}_{t}, \\
\lambda_{t} \geq 0 \mathrm{t} \in\{1, \ldots, \mathrm{T}\}, \\
\theta \text { free. }
\end{gathered}
$$

\subsubsection{Performance}

Similar to before, we use that performance measure (8) can be written equivalently as

$$
\operatorname{Perf}_{E}=\min _{\theta \in \mathbb{R}}\left\{\theta \mid\left(\theta, \mathbf{y}_{E}\right) \in \hat{P}^{\prime}\right\} .
$$

Taken together, (7) and (10) define the empirical measure $\widehat{\operatorname{Perf}}_{E}$ as the outcome of a linear program:

$$
\begin{gathered}
\widehat{\operatorname{Perf}}_{E}=\min \theta \\
\text { s.t. } \theta \geq \sum_{\mathrm{t}=1}^{\mathrm{T}} \lambda_{\mathrm{t}}, \\
\mathbf{y}_{E} \leq \sum_{t=1}^{T} \lambda_{t} \mathbf{y}_{t}, \\
\lambda_{t} \geq 0 \text { for all } \mathrm{t} \in\{1, \ldots, T\}, \\
\theta \text { free. }
\end{gathered}
$$

(Perf1

In a final step, we can drop the variable $\theta$ and the constraint (Perf_1) as redundant, which leads to the following equivalent formulation:

$$
\begin{gathered}
\widehat{\operatorname{Perf}}_{E}=\min \sum_{t=1}^{T} \lambda_{t} \\
\text { s.t. } \mathbf{y}_{E} \leq \sum_{t=1}^{T} \lambda_{t} \mathbf{y}_{t}, \\
\lambda_{t} \geq 0 \text { for all } t \in\{1, \ldots, T\} .
\end{gathered}
$$

(PerfLP2

(Perf2

\subsection{Dual representations}

\subsubsection{Productivity}

Let the vectors $\mathbf{p}_{E} \in \mathbb{R}_{+}^{N}$ and $\mathbf{w}_{E} \in \mathbb{R}_{+}^{M}$ represent the shadow prices for the constraints (Prod_1) and (Prod_2), respectively. Then, the dual of the linear program (Prod_LP) is as follows:

$$
\begin{gathered}
\operatorname{Prod}_{E}=\max \mathbf{w}_{E} \mathbf{y}_{E} \\
\text { s.t. } \\
\mathbf{p}_{E} \mathbf{x}_{E}=1, \\
\mathbf{w}_{E} \mathbf{y}_{t}-\mathbf{p}_{E} \mathbf{x}_{t} \leq 0 \text { for all } \in\{1, \ldots, T\}, \\
\mathbf{p}_{E} \in \mathbb{R}_{+}^{N}, \mathbf{w}_{E} \in \mathbb{R}_{+}^{M} .
\end{gathered}
$$

(ProdLP3

It is easy to verify that this allows us to define $\widehat{\operatorname{Prod}}_{E}$ as

$\widehat{\operatorname{Prod}}_{E}=\max _{\mathbf{p}_{E} \in \mathbb{R}_{+}^{N}, \mathbf{w}_{E} \in \mathbb{R}_{+}^{M}}\left\{\frac{\mathbf{w}_{E} \mathbf{y}_{E}}{\mathbf{p}_{E} \mathbf{x}_{E}} \mid \frac{\mathbf{w}_{E} \mathbf{y}_{t}}{\mathbf{p}_{E} \mathbf{x}_{t}} \leq 1\right.$ forall $\left.t \in\{1, \ldots, T\}\right\}$,

which implies a specific interpretation for $\widehat{\operatorname{Prod}}_{E}$ as the ratio of a weighted outcome sum over a weighted resource sum. A particular feature is that the resource and outcome weights are chosen so as to maximize this ratio, which effectively gives the "benefit-of-the-doubt" to the evaluated DMU E. ${ }^{7}$

Next, the normalization constraint $\left(\frac{\mathbf{w}_{E} \mathbf{y}_{t}}{\mathbf{p}_{E} \mathbf{x}_{t}} \leq 1\right)$ imposes that the maximum attainable productivity ratio over the sample of $T$ DMUs equals unity. This feature effectively yields an intuitive degree interpretation for $\hat{\operatorname{Prod}}_{E}$ : using the weights $\mathbf{w}_{E}$ and $\mathbf{p}_{E}$ defined by the program (using benefit-of-the-doubt), 
it represents DMU E's input-outcome ratio (at most equal to unity) as a proportion of the best achievable ratio in the observed sample of DMUs (which is fixed at unity).

\subsubsection{Performance}

Interestingly, we can derive an analogous benefit-ofthe-doubt interpretation for our performance measure $\hat{P e r f}_{E}$. Following our previous exposition, the basic difference is that resource constraints are ignored in the evaluation exercise.

Similar to before, we let $\mathbf{v}_{E} \in \mathbb{R}_{+}^{M}$ represent the shadow prices for the constraint (Perf_2). Then, the dual of the program (Prod_LP) is defined as follows:

$$
\begin{gathered}
\widehat{\operatorname{Perf}}_{E}=\max _{E} \mathbf{y}_{E} \\
\text { s.t. } \mathbf{v}_{E} \mathbf{y}_{t} \leq 1 \text { for all } t \in\{1, \ldots, T\}, \mathbf{v}_{E} \in \mathbb{R}_{+}^{M} .
\end{gathered}
$$

(PerfLP3)

In short, we thus obtain

$$
\widehat{\operatorname{Perf}}_{E}=\underset{\mathbf{w}_{E} \in \mathbb{R}_{+}^{M}}{ }\left\{\mathbf{v}_{E} \mathbf{y}_{E} \mid \mathbf{v}_{E} \mathbf{y}_{t} \leq 1 \text { for all } t \in\{1, \ldots, T\}\right\},
$$

which represents $\widehat{\operatorname{Perf}}_{E}$ as a weighted sum of outcomes. Once more, the weights are chosen to maximize this sum, which implies benefit-of-the-doubt weighting. In this case, the normalization constraint $\left(\mathbf{v}_{E} \mathbf{y}_{t} \leq 1\right)$ imposes a maximum outcome sum value of unity for the sample of $T$ DMUs, which again provides an intuitive degree interpretation to the measure $\widehat{\operatorname{Perf}}_{E}$.

\subsection{Robust and conditional estimation}

\subsubsection{Robust estimation}

As discussed in Section 2.1, so far we have assumed that resources and outcomes are measured without errors. Obviously, this assumption may be problematic in empirical applications. As measurement errors can shift significantly the production set $\hat{P}$, they can bias $\widehat{\operatorname{Prod}}_{E}$ and $\widehat{\operatorname{Perf}}_{E}$. Removing the DMUs with measurement errors from $\hat{P}$ is usually not an option, mainly because of the following two reasons. First, we often do not know which observations are prone to measurement errors. Second, by simply dropping the observations with outlying values for resources and outcomes we might in fact falsely remove the most interesting observations from the sample.

Cazals, Florens, and Simar (2002) and Daraio and Simar (2005) proposed a method to mitigate the influence of outlying observations and/or observations with measurement errors in applications using the Free Disposal Hull model (i.e., DEA without convexity constraint). Daraio and Simar (2007) extended this to DEA. This method is readily adapted to our productivity and performance measures. In particular, we estimate $\widehat{\operatorname{Prod}}_{E}$ and $\widehat{\operatorname{Perf}}_{E}$ relative to an empirical production set $\widehat{P}_{m}$ that is based on a strict subset of $m$ observations that is drawn (randomly and with replacement) from the observations $t \in\{1, \ldots T\}$ with $x_{t} \leq x_{E}$. Let us denote the resulting estimates as $\widehat{\operatorname{Prod}}_{E, m}^{b}$ and $\widehat{\operatorname{Perf}}_{E, m}^{b}$. Then, we redo this estimation of $\widehat{\operatorname{Prod}}_{E, m}^{b}$ and $\widehat{\operatorname{Perf}}_{E, m}^{b}$ a large number of times (say $B$ times, with $B>2000$ ), and we average these $B$ productivity and performance estimates. The obtained averages $\widehat{\operatorname{Prod}}_{E, m}$ and $\widehat{\operatorname{Perf}}_{E, m}$ are called robust order- $m$ efficiency estimates. Basically, they are robust because outlying observations and observations with measurement errors will typically not define the empirical set $\widehat{P}_{m}$ in every draw $b$. Thus, we have effectively mitigated their influence.

As a final remark, it is also possible that the evaluated observation $E$ does not belong to the set $\widehat{P}_{m}$. As an implication, the values of $\widehat{\operatorname{Prod}}_{E, m}$ and $\widehat{\operatorname{Perf}}_{E, m}$ may well exceed 1 . If this is the case, we label DMU $E$ as "super-efficient." Basically, a super-efficient DMU is (on average, over the $B$ draws) better performing than the $m$ randomly drawn observations. It is interesting to observe that the robust and deterministic estimates will converge as $m \rightarrow \infty$ (i.e., $\widehat{\operatorname{Prod}}_{E, m} \rightarrow \widehat{\operatorname{Prod}}_{E}$ and $\widehat{\operatorname{Perf}}_{E, m} \rightarrow \widehat{\operatorname{Perf}}_{E}$ ). The parameter $m$ serves as a trimming value, which allows us to tune the percentage of super-efficient observations. In our next application, we will follow Daraio and Simar (2005) to fix $m$ at its value for which the marginal decrease in the fraction of super-efficient observations becomes sufficiently small (see Appendix 1 for details).

\subsubsection{Conditional and robust estimation}

A second issue related to the practical implementation of the programs (Prod-LP3) and (Perf_LP3) concerns inter-DMU heterogeneity in terms of production environments. Clearly, DMUs that can operate in a favourable environment have an advantage; the environment works as a substitutive input, and $\widehat{\operatorname{Prod}}_{E, m}$ and $\widehat{\operatorname{Perf}}_{E, m}$ will be upward biased. Conversely, DMUs working in an unfavourable environment will have to put more efforts as the environment works as a substitutive output. In what follows, we assume that a DMU's operational environment is summarized by the $s$-dimensional vector $z \in \mathbb{R}_{+}^{S}$.

Daraio and Simar $(2005,2007)$ suggest to include the operational environment by extending the robust order- $m$ procedure of Cazals et al. (2002). ${ }^{8}$ Like before, the refined procedure draws the $m$ observations with replacement from the observations 
$t \in\{1, \ldots T\}$ with $x_{t} \leq x_{E}$. But now it attaches to each observation a particular probability, which is defined on the basis of a multivariate kernel function around $z_{E}$ (which characterizes the environment of DMU E). Basically, observations which are more similar to DMU $E$ in terms of their operational environment are drawn with greater likelihood. Similar to before, a given draw $b$ of observations defines an empirical production set $\widehat{P}_{m}^{Z}$, for which we can compute the estimates $\widehat{\operatorname{Perf}}_{E, m}^{Z, b}$ and $\widehat{\operatorname{Perf}}_{E, m}^{Z, b}$. Again, we redo this $B(>2000)$ times to obtain $\widehat{\operatorname{Prod}}_{E, m}^{Z}$ and $\widehat{\operatorname{Perf}}_{E, m}^{Z}$. $\widehat{\operatorname{Perf}}_{E, m}$ It follows that these so-called "conditional robust" estimates effectively compare like with likes, by explicitly accounting for the operational environment.

In the estimation of the conditional robust productivity and performance measures, the choice of kernel function and corresponding bandwidth are of vital importance. In our following application, we will follow Witte and Kortelainen (2013), who suggested to use the Li and Racine (2007) discrete kernel function with a data driven bandwidth $h$ as in Bădin, Daraio, and Simar (2010) and Li and Racine (2007). As an advantage, this bandwidth can remove irrelevant covariates by oversmoothing them.

As a concluding note, we indicate that accounting for measurement errors by improving robustness to outliers may sometimes be an unsatisfactory solution. Implicitly, it assumes that there are a few erroneous observations (i.e., the "outliers") that are difficult to identify, but the majority of observations are observed without error. This assumption is problematic if all observed data are subject to error. In such cases, even if the robust production set approximates the true production set reasonably well, measuring inefficiency as the a DMU's performance relative to the estimated production set ignores measurement error in the data of the DMU itself. See, for example, Kuosmanen and Kortelainen (2012) and Kuosmanen and Johnson (2017) for nonparametric methods (based on convex regression) that allow one to explicitly model measurement error in all data points. We see the extension of these methods towards our performance/productivity framework as a valuable avenue for followup research.

\section{Data}

We demonstrate the practical usefulness of our methodology through an application to secondary schools in the Netherlands. As we will argue, we can use detailed resource, outcome and environmental data that are very well suited for the practical implementation of our methodology. Moreover, and importantly, the type of conclusions that can be drawn from the performance-productivity analysis that we introduced above are directly relevant for this policy setting. In this section, we first introduce our data sources, and subsequently motivate our selection of resources, outcomes and control variables (which characterize the DMUs' operational environment).

\subsection{Data sources}

We apply our methodology to a rich administrative dataset from Dutch secondary schools. The data originate from two sources. First, we retrieved data from the Dutch ministry of Education, Culture and Sciences, which publishes comparable information at school level. We use the school year 2011-2012. This information provides us with insights in the educational attainments of the school, the allocation of the school budget and the composition of the school in terms of share of students from disadvantageous backgrounds. In addition, we have information on two types of educational attainments of students: the school average of the national exam and the school exam. In the final years of secondary education, all students in the Netherlands have to take two exams for each course that they took (independent of the educational track). The former exam - the "national exam" - is an absolute assessment with criterion-referencing that is uniform for all subjects and schools in the Netherlands (see Witte, Geys, \& Solondz, 2014, for a discussion). The latter exam - the "school exam" - has fewer quality controls in its construction and evaluation as it is set up and corrected only by a school's teachers. Aggregate information on the school and national exam is publicly available.

We augment this first data source with unique pupil level data for more than 12,800 students in 80 schools. The data are unique as they accurately trace the performance of middle school students on math exercises. Dutch schools pay increasingly attention to math due to some recently formulated performance standards (Commissie Meijerink, 2008). We can distinguish four domains in mathematics: numbers, proportions, measurement, and associations. To practice these domains, a national publisher (ThiemeMeulenhoff) has developed an innovative computer-assisted instruction (CAI) tool, called Gotit?! The program offers a wide range of exercises of different difficulty levels. It is an adaptive program as it adjusts its exercises to the knowledge and the level of the student. This allows the teacher to differentiate within the class (an extensive discussion and effectiveness study of this program is provided in Witte et al., 2014). We have access to the logged data of all 80 schools that are using this tool. In 
Table 1. Summary statistics for inputs, outputs, and control variables.

\begin{tabular}{|c|c|c|c|c|c|c|c|c|}
\hline Variable & $n$ & Mean & S.D. & Min. & 0.25 & Median & 0.75 & Max. \\
\hline \multicolumn{9}{|l|}{ Input variables } \\
\hline Cost of material per student $(€)$ & 80 & 914.94 & 254.26 & 488.37 & 746.12 & 887.96 & 1033.58 & 1676.25 \\
\hline Cost of teachers per student $(€)$ & 80 & 6434.93 & 993.22 & 4895.54 & 5962.24 & 6302.84 & 6703.71 & $12,523.56$ \\
\hline Cost of housing per student $(€)$ & 80 & 504.89 & 212.83 & 254.39 & 392.52 & 474.69 & 555.54 & 1868.95 \\
\hline Time devoted to math exercises (hours) & 80 & 45.36 & 40.16 & 1.5 & 14.1 & 29.91 & 78.67 & 178.57 \\
\hline \multicolumn{9}{|l|}{ Output variables } \\
\hline Average score on the math exercises & 80 & 16.34 & 15.58 & 0.81 & 4.59 & 8.78 & 28.11 & 65.86 \\
\hline Average on the standardized exam & 80 & 6.45 & 0.3 & 5.6 & 6.3 & 6.4 & 6.65 & 7.35 \\
\hline \multicolumn{9}{|l|}{ Control variables } \\
\hline$\%$ of students disadvantaged neighbourhoods & 80 & 5.95 & 9 & 0 & 0.13 & 1.9 & 8.05 & 41.8 \\
\hline Average age of the teachers & 80 & 45.08 & 2.09 & 39.7 & 43.8 & 45.05 & 46.3 & 49.6 \\
\hline $\begin{array}{l}\text { Average score of standardized exam } \\
\text { at end of primary education }\end{array}$ & 80 & 99.38 & 5.76 & 83.97 & 96.15 & 99.42 & 102.95 & 117.67 \\
\hline
\end{tabular}

particular, we observe the time that students devote to math exercises, and the test results of the exercise. The time can be interpreted as a proxy for ability as more able students can comply the exercises more quickly than less able students.

One caveat should be taken into account. For the unique pupil level data, we only consider students in the third year of secondary education (comparable to middle school). From the administrative data, the information concerns all incoming and outgoing students of the school. In other words, the underlying students are different for the different variables. Nevertheless, this creates insightful information as the full education process at the school is included: from exogenous (at least for the school) abilities at the start of secondary education, through the performance and heterogeneity in the middle of secondary education, until the standardized test results at the end of secondary education.

\subsection{Outcomes, resources, and control variables}

Society expects that schools deliver value for money. We measure the outcomes of schools by two variables. First, the average score obtained by the standardized school exam (average for all courses) at the end of secondary education. As the exam is taken simultaneously for all students, and as it is independently corrected by two teachers, it can be easily compared between schools. As a second outcome variable, we consider the average exercise score for math in the third year of secondary education (Witte et al., 2015). This score is obtained from the average on the exercises from the computer-assisted tool. The outcomes indicate that schools have to maximize final and intermediate outputs. As revealed in the literature review on efficiency in education by Witte and Lopez-Torres (2017), these outcome variables are commonly used in earlier work. ${ }^{9}$

In the model with resource constraints, we consider four resources. The resources reflect the monetary and time costs for education. Dutch schools receive a lump sum subsidy per student by the central government. They are relatively free to allocate the money. As a first resource variable, we use the costs for teachers per student. This reflects the teaching capacity. It can be compared to the traditional number of teachers per student. As a second and third resource variable, we use the cost of materials per student and the cost of housing per student. These variables provide a proxy for the available facilities at the school. Finally, in line with the traditional education production function we include the time for education. As suggested by Hanushek (1995) one should not include" the time spent in schools without judging what happens in schools," but rather include a precise measure of time use. Therefore, we include the time that students spend on the math exercises. The latter variable allows us to capture the heterogeneity in abilities among students (i.e., less able students will spend more time on math exercises). As all 80 schools in the sample use the computer-assisted tool, the variable can be easily compared among the schools. ${ }^{10}$

A final set of variables capture the heterogeneity in the schools' operational environments. We consider three variables which we assume represent resources out of schools' control. A first variable measures the quality of the student intake. At the end of primary education, students have to make a compulsory (although there are some minor exceptions) standardized central exam. Together with the advice from the primary school teacher, the score on this centralized so-called "cito-exam" provides a binding advice for the secondary education track a student has to follow. As a second control variable, we include the average age of the teachers. In line with earlier literature (see Witte \& Lopez-Torres, 2017), this serves as a proxy for the experience of teachers. Finally, we include the percentage of students coming from disadvantaged neighbourhoods. These neighbourhoods are defined by Statistics Netherlands. This variable can explain the cultural and societal abilities of students. If a school attracts more students from disadvantaged neighbourhoods, it can be expected that it has different issues to deal with than schools with a more favourable student population. 
Table 2. Productivity measures.

\begin{tabular}{lcc}
\hline & Robust & Conditional \\
\hline Minimum & 0.2172 & 0.2281 \\
$25 \%$ & 0.4802 & 0.4998 \\
Average & 0.7306 & 0.7497 \\
St. Deviation & 0.2997 & 0.3157 \\
$75 \%$ & 0.9859 & 1.0073 \\
Maximum & 1.3576 & 1.7709 \\
\hline
\end{tabular}

Table 3. Performance measures.

\begin{tabular}{lcc}
\hline & Robust & Conditional \\
\hline Minimum & 0.2846 & 0.2850 \\
$25 \%$ & 0.6422 & 0.6398 \\
Average & 0.7825 & 0.7831 \\
St. Deviation & 0.1983 & 0.1985 \\
$75 \%$ & 0.9486 & 0.9482 \\
Maximum & 1.0260 & 1.0314 \\
\hline
\end{tabular}

Table 1 provides summary statistics for our three categories of variables. Concerning the resources, a large majority of the lump sum budget is devoted to teaching staff. On average, schools spend about seven times as much per student on teachers than on materials or housing. The time devoted to math exercises varies significantly over the schools. Some schools pay a lot of attention to math exercises, whereas other schools are more restrictive in the time for math exercises.

The descriptive statistics of the outcomes variables exhibit an interesting heterogeneity across schools. We find significant differences between the best and worst performing schools in terms of both the average scores for math exercises and the standardized exam. Also the inequality in the math scores is relatively large between schools.

These differences might at least partly be explained by heterogeneity in the schools operational environments (which is captured by our control variables). For example, the sample includes schools without any student from disadvantaged neighbourhoods as well as schools with no less than $41 \%$ of such students. We also observe significant variation in the average exam scores at the end of primary education. Finally, the age difference among teachers is, on average, almost 10 years. These interschool differences directly motivate the need to account for the operational environment in our performance-productivity analysis.

\section{Empirical results}

In this section, we will first consider our productivity and performance results separately. Subsequently, we will investigate the performance/ productivity ratios of the schools under study and show that these ratios give rise to a number of interesting insights (regarding unexploited capacity versus resource constraints hampering schools' performances).

\subsection{Productivity versus performance}

\subsubsection{Productivity}

We begin by studying schools' productivity scores, which account for differences in resources among schools. As indicated in our discussion of the descriptive statistics (in Table 1), despite similar budget and time constraints (i.e., lump sum per student as well as total number of teaching hours are roughly the same across schools), we do observe significant heterogeneity in the way resources are used (i.e., differences in teaching outcomes). The productivity results are presented in Table 2 . The first column in this table shows the "robust" results, while the second column presents the conditional and robust (in short "conditional") results. The former ignores the operational environment, while the latter apply the conditional approach that we set out at the end of Section 3.

Let us first consider the robust results. These results indicate that the average school has a productivity shortfall of $27 \%$. In other words, for the given resources, a school could (on average) increase its productivity by $27 \%$ if it would produce at its best practice level. The best performing schools are super-efficient. As explained in Section 3, this indicates that these schools are performing better than their randomly drawn reference observations in the order- $m$ procedure (i.e., robust score above unity). More precisely, the best performing school performs $35 \%$ better than its reference (averaged over all random draws). Next, when we look at the first quartile, we find that $25 \%$ of the schools performs more than $52 \%$ worse than their reference. Finally, the minimal productivity value is as low as $22 \%$, which suggests that the worst performing school can massively increase its productivity.

Importantly, however, these results do not account for differences in the schools' operational environments. If we do take such environmental differences into account, only a slightly different picture emerges. It does not seem that the differences between the schools further enlarges or decreases. The average school can improve by $25 \%$, while still a quarter of the schools can improve by more than $50 \%$ in educational attainments. Despite the use of the order- $m$ methodology, which mitigates the influence of outlying observations, some schools are clearly super-(in)efficient.

\subsubsection{Performance}

In a following step, we ignore inter-school differences in resources and consider "performance" scores. The results are presented in Table 3, which shows that ignoring the resources delivers a more benevolent model. While the average performance increases 
Table 4. Performance/productivity ratios.

\begin{tabular}{lcc}
\hline & Robust & Conditional \\
\hline Minimum & 0.3439 & 0.3602 \\
$25 \%$ & 0.8535 & 0.8519 \\
Average & 1.2178 & 1.1897 \\
St. Deviation & 0.4701 & 0.4643 \\
$75 \%$ & 1.4961 & 1.4402 \\
Maximum & 2.6558 & 2.6630 \\
\hline
\end{tabular}

in comparison to the productivity model, there are less super-efficient observations. On average, a school could increase its educational attainments by $22 \%$ if it would perform as efficient as its reference outcome. The observation with the lowest performance could improve by as much as $72 \%$. About $25 \%$ of the schools have a performance shortfall of less than $6 \%$.

A similar picture emerges for the conditional performance estimations, which are, again, well comparable to the robust performance estimations. It is actually quite remarkable that the robust and conditional estimates are that similar. This suggests that the schools' operational environments do not significantly impact their output performance. This is confirmed by additional analyses in which we set out (non-parametrically) how the ratio of robust over conditional performance estimates relate to school characteristics "\% of students from disadvantaged neighbourhoods," "average age of the teachers," and "average score of standardized exam at the end of primary education" (using a procedure proposed by Witte \& Kortelainen, 2013). For this exercise, we find that none of these variables shows a significant relationship to the (robust over conditional) performance ratio. ${ }^{11}$

\subsection{Performance/productivity ratios}

By comparing the performance and productivity estimates, we can obtain insights into the prevalence of resource constraints versus unexploited capacity. The results for the ratios $\hat{\operatorname{Prod}}_{E, m} / \hat{\operatorname{Perf}}_{E, m}^{Z}$ and $\widehat{\operatorname{Perf}}_{E, m}^{Z} / \widehat{\operatorname{Prod}}_{E, m}^{Z}=\alpha+\beta X_{E}+\epsilon_{E}$ are summarized in Table 4. We observe that there are schools for which we can expect more outcome gain from a weaker resource constraint (i.e., the ratio is below unity) as well schools which can increase the educational attainments when the resource variation is disregarded (i.e., the ratio is above unity). Interestingly, the "average" school corresponds to the latter scenario, which suggests that a majority of schools does not fully exploit the production capacity. The conditional scores in Table 4 reveal that this conclusion is not impacted by heterogeneity in schools' operational environments.

As a further investigation, we present the performance/productivity ratios as a function of the underlying performance and productivity scores.
This is visualized in Figure 3. Some interesting patterns emerge. Specifically, the schools that are mainly hampered by scarce resources are often super-efficient in terms of the productivity measure. For the given resources, these observations are doing better than expected, which may signal "resource over-utilization." Those observations would benefit from weaker resource constraints. By contrast, the schools with unexploited capacity (or "resource under-utilization") are predominantly those which combine low productivity with high performance. Those observations would benefit from more stringent resource constraints, because less resources need not impact the output performance.

The question remains which are the characteristics of the schools with unexploited capacity (or resource under-utilization) and those which are faced by resource constraints (or resource over-utilization). To address this issue, we estimate the following model:

$$
\operatorname{Perf}_{E, m}^{Z} / \operatorname{Prod}_{E, m}^{Z}=\alpha+\beta X_{E}+\varepsilon_{E}
$$

where $\alpha$ denotes a constant, $\beta$ vector with coefficients of the observed characteristics $X$ of observation $E$, and $\varepsilon_{E}$ an i.i.d. error term. Given the significant differences in under and over-utilization of resources (see Table 4), we estimate model (11) by a quantile analysis. A standard OLS regression would focus on the conditional mean of the performance/productivity ratio without accounting for its full distributional properties. On the contrary, a quantile regression estimates the potentially differential effect of an independent variable $X$ on various quantiles in the conditional distribution (Koenker \& Bassett, 1978). As observed characteristics we include variables which have been indicated in earlier literature (see overview by Witte \& LopezTorres, 2017) to influence the productivity and performance of schools. They include (1) the number of students per teacher, (2) the school size (number of students in the school), (3) the number of school managers in full time equivalents (FTE), (4) the number of school locations per school district or governing body, and (5) the percentage of early school leavers, defined as students who leave the school without higher secondary degree and do not enrol in further education or training. The descriptive statistics are presented in Table 5. They show some significant heterogeneity across the schools. For example, some schools have clearly more students per teachers than other schools. Given the relative autonomy of Dutch schools in spending the lump sum budget, it is intuitive that we observe a negative correlation $(-0.14)$ between the number of 


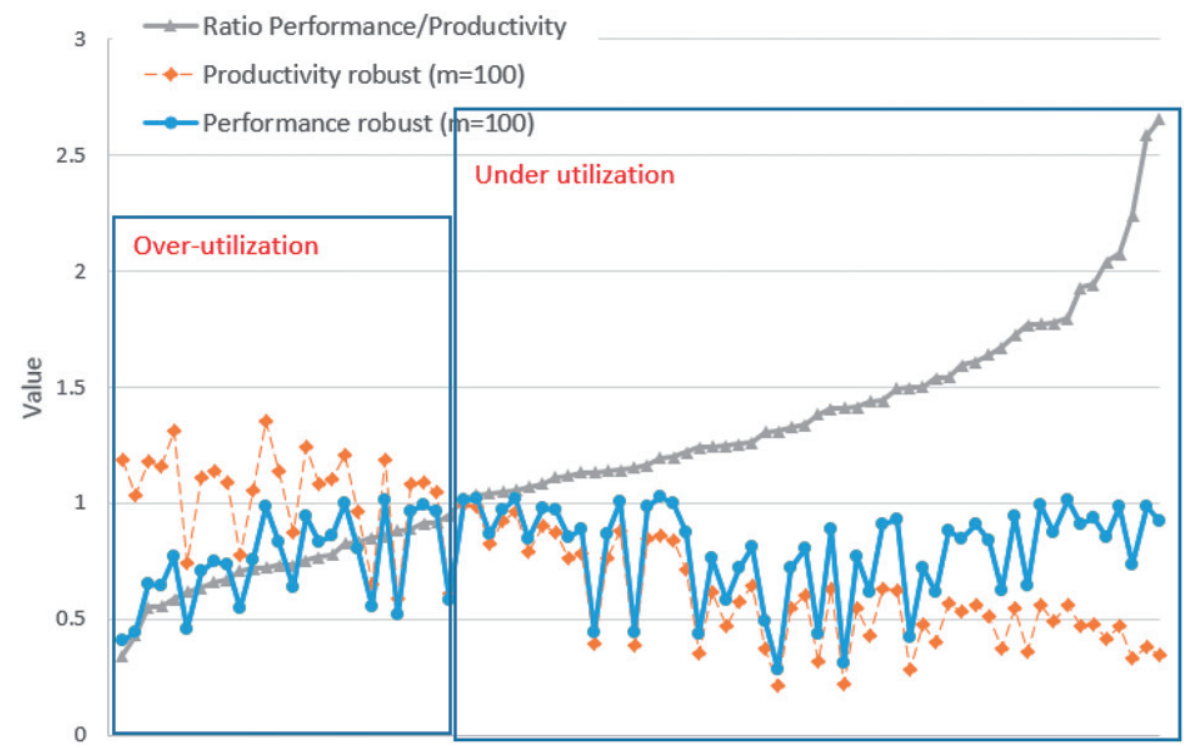

Figure 3. Resource utilization.

Table 5. Descriptive statistics of variables which explain the performance/ productivity ratio.

\begin{tabular}{lcrrrr}
\hline & Obs & Mean & Std. Dev. & \multicolumn{1}{c}{ Min } & \multicolumn{1}{c}{ Max } \\
\hline Students per teacher & 80 & 15.29 & 1.84 & 9.64 & 19.34 \\
School size & 80 & 2370.93 & 1064.07 & 400.00 & 5641.00 \\
Managers at school (FTE) & 80 & 10.50 & 8.54 & 0.00 & 39.80 \\
Nr. school locations at governing body & 80 & 7.19 & 11.11 & 1.00 & 35.00 \\
Early school leaving (\%) & 80 & 1.31 & 0.71 & 0.00 & 4.58 \\
\hline
\end{tabular}
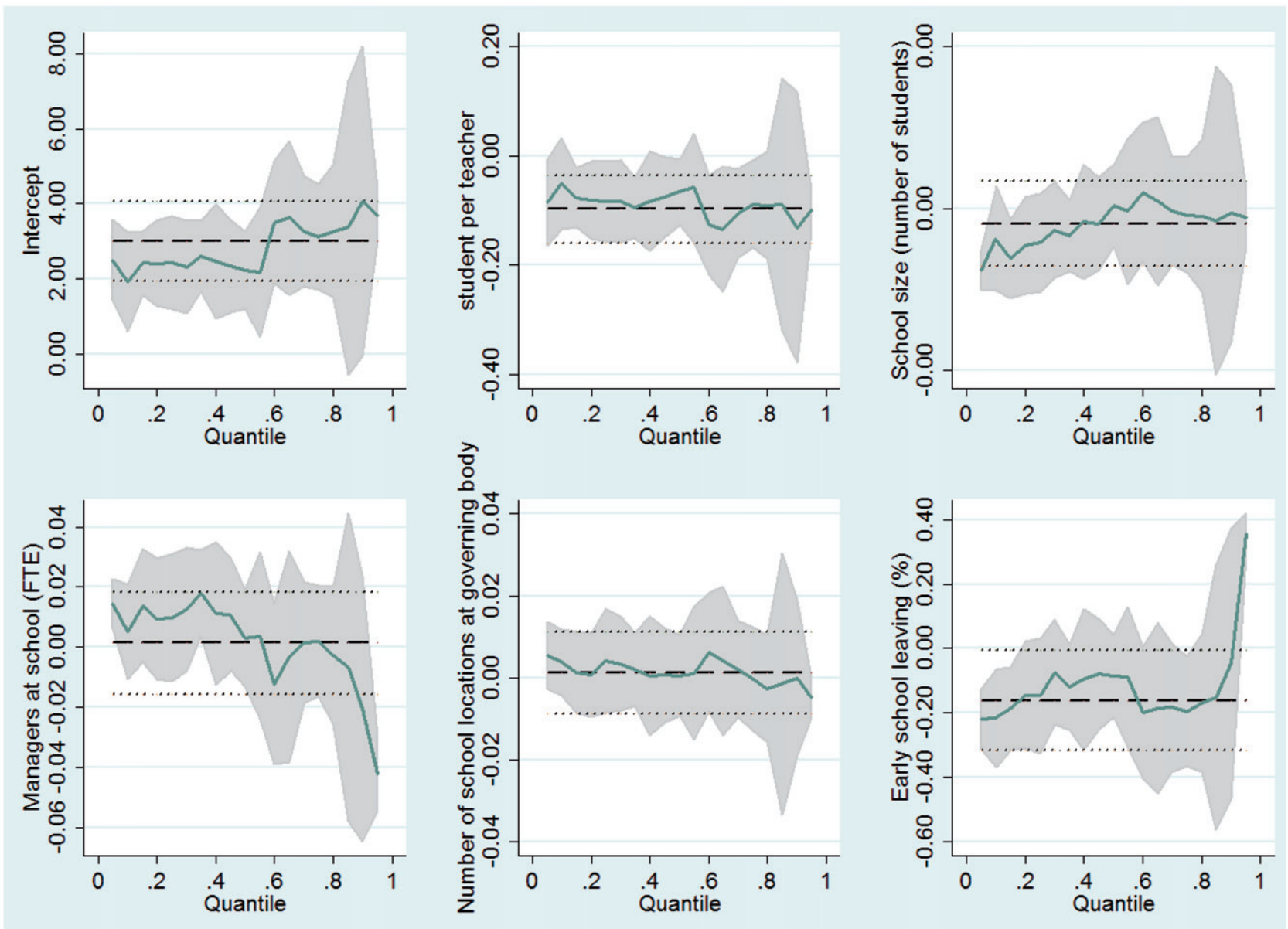

Figure 4. Quantile analysis. 
students per teacher and the number of managers at a school (expressed in FTE).

While this regression lacks sufficient power to obtain statistically significant outcomes, we do observe some noteworthy patterns. We report in Figure 4 the graphs of the coefficients of the quantile analysis. Each figure reports for each parameter the complete picture, that is the values each parameter takes, from quantile 0.01 to quantile 1.00 . The grey areas denote the 95\%-confidence interval around the estimates.

The negative sign in the first graph (student per teacher) suggests that more students per teacher generally corresponds to less unexploited capacity (over-utilization of resources). The estimated correlation is roughly similar for all quantiles of the student-teacher ratio. This suggests that the number of students per teacher does vary with having weaker or stronger resource constraints.

Second, smaller schools (in terms of student numbers) are characterized by less unexploited capacity, which is not the case for the larger schools. It is interesting to observe that the estimated coefficient slightly increases with the quantile of the number of students at a school. This suggests that larger schools have more unexploited capacity, although the confidence interval around the estimate also increases dramatically (due to fewer observations of large schools).

Third, we observe a decreasing pattern for the relationship between the number of school managers (in FTE) and the performance/productivity ratio. For the first quantiles of the number of school managers, we observe a positive (insignificant) correlation to the performance/productivity ratio. This suggests that schools with few managers have a greater degree of unexploited production capacity or technical inefficiency. By moving along the quantiles of the number of school managers the coefficients of the quantile analysis decrease and even become negative. This suggests that for schools with more managers, we can expect more output gains from weaker resource constraints.

Fourth, the number of schools per governing body (school district) does not exhibit a significant correlation with the performance/productivity ratio. Confidence intervals are fairly large for all quantiles and, correspondingly, the estimated coefficient is generally close to zero.

Finally, the percentage of early school leavers (school dropouts) correlates negatively and (for some quantiles) significantly to the performance/ productivity ratio. These results suggest that early school leaving correlates to resource constraints restricting school performance, which implies that more output gain can be expected from weaker resource constraints. However, while the coefficient is negative for most quantiles of school dropouts, it is positive for the highest quantiles. Although largely insignificant, this finding indicates that schools with a high percentage of early school leavers also have a large degree of unexploited production capacity.

\section{Conclusion}

Performance of public sector services may be hampered by resource constraints, or may be characterized by unexploited capacity. We have presented a novel and simple framework to evaluate the public sector performance in view of these issues. Our method computes performance/productivity ratios and can be implemented as soon as data on production units' outcomes and resources are available. Ratio values below unity indicate that better outcomes can be attained through weaker resource constraints (pointing at scarcity of resources) and, conversely, ratio values above unity indicate that better outcomes can be achieved with the same resources (pointing at unexploited production capacity).

We have demonstrated the practical usefulness of our methodology through an application to secondary schools in the Netherlands. In this application, we also account for outlier behaviour and environmental effects by using a robust and conditional nonparametric estimation method. Our empirical results indicate that in most cases schools' performance improvement is a matter of unexploited production capacity, while scarcity of resources is a lesser issue. It provides an argument for educational policy makers in times of austerity. While there are schools that do suffer from stringent resource constraints, the majority of the schools should first increase their productivity before requesting additional funding.

We have also investigated the characteristics of the schools with unexploited capacity and with binding resource constraints. First, we found that under-utilization of resources is positively related to the number of school managers. This finding is in line with the substantial increase of the number of middle managers in the Netherlands. Due to a consolidation of the number of school districts (i.e., more schools per governing body), we could observe an increase in the number of school managers. Our analysis suggests that many schools would benefit from a reduction of the number of managers. Next, scarcity of resources bears a positive association with the number of students per teacher. This observation provides a hands-on tool for policy makers to analyse the over-utilization of resources. Combing this finding with the previous one, it can 
be argued that schools with a high number of students per teacher and a low number of school managers operate under serious resource constraints.

Furthermore, larger schools also seem to suffer from scarce resources. These schools are often located in urban areas, such that they face various challenges due to their unfavourable socioeconomic position. In addition, larger schools typically have a higher complexity, which should be compensated by additional resources. Lastly, resource over-utilization correlates positively to the number of students who leave school without a higher secondary degree and who are not further enrolled in education or training. This suggests that the more early school leavers a school has, the less unexploited capacity there will be. Schools with stringent resource constraints seem to be unable to monitor and prevent early school leaving. Given the substantial societal costs of early school leaving, this suggests that governments should make sure that they provide sufficiently large resources to schools to prevent this from happening.

As a concluding remark, while our application in the current paper has focused on education, we emphasize that our methodology can also be relevant in other regulatory contexts. In this respect, a notable example concerns the provision of public services in developing countries. As stated by Estache and Wren-Lewis (2009), "The efficient operation and expansion of infrastructures in developing countries is crucial for growth and poverty reduction." Mbuvi, De Witte, and Perelman (2012), for instance, computed simultaneously performance and productivity of water distribution utilities in Africa and showed that there was room for dramatic improvements, near $40 \%$, in both performance and productivity, with the solution relying in most cases on technical inefficiencies rather than on resource constraints.

\section{Notes}

1. For an overview, see Cherchye et al. (2007).

2. Among factors affecting public service performance, Witte and Geys (2013) emphasize the role of consumers' coproduction, in an application to public libraries.

3. We adapt the traditional approach, applied to firm's production, to the particular case of public services. For this purpose, the output-input setting is replaced by the outcome-resource setting.

4. We remark that we may also have used alternative returns-to-scale assumptions. One motivation for assuming constant returns-to-scale is that it allows for an intuitive (dual) interpretation of our productivity-performance measures in terms of "benefit-of-the-doubt" weighting, which we explain in Section 3.2. Another motivation, more practical, is that outcomes and resources will be generally represented by indicators, ratios or per-capita values, as in the example presented in next sections. Anyway, the methodology can be straightforwardly extended to the case of productivity measurement under variable returns-to-scale, which allows for distinguishing between scale efficiency and pure technical efficiency. We will illustrate this by means of a simple numerical and graphical example at the end of this section.

5. See also Lovell and Pastor (1999), for a detailed discussion on productivity measurement with constant input. Lovell et al. (1995) used the helmsman interpretation in the context of macroeconomic policy evaluation. Here, we use the same idea in the context of output assessments of micro-DMUs. As a specific example, our following empirical application will use the idea for a school performance assessment that focuses on educational outputs per pupil. Formally, our performance based method is the same is the one used by Collier, Johnson, and Ruggiero (2011) to aggregate outputs while assuming constant input. A main difference between the two approaches, is that, like in Lovell et al. (1995), we interpret the solution value of (8) directly as a relative performance measure, whereas Collier et al. (2011) use (8) as a measure of aggregate output, which is then incorporated into a second-stage regression-based analysis of technical efficiency.

6. For brevity, we do not include a full formal treatment of the variable returns-to-scale case. The variable returns-to-scale DEA model for productivity analysis was first introduced by Banker et al. (1984) and has been widely used in the literature. We refer to Banker et al. (1984) for formal details.

7. We remark that the ratio formulation of $\widehat{\operatorname{Prod}}_{E}$ actually expresses this measure as maximizing "profitability" (i.e. revenue over cost), a concept that is often used in the literature on productive efficiency measurement [see, for example, GrifelTatjé and Lovell (2015)].

8. At this point, we remark that alternative methods to deal with heterogeneous operational environments have been proposed in a DEA context. See, for example, Banker and Morey (1986) and Ruggiero (1996), who specifically focused on controlling for exogenous/socio-economic conditions in a public sector context (similar to our own application in Section 4). In fact, the conditional efficiency approach builds further on insights from Banker and Morey (1986) and Ruggiero (1996) While we here choose to use the robust order- $m$ procedure of Daraio and Simar $(2005,2007)$, it is worth noting that our method is also easily adapted to these alternative DEA-based procedures.

9. It should be noted that this application uses a CRS assumption. There is a rich literature that compares constant (CRS), variable (VRS), decreasing (DRS) and/or increasing (IRS) returns-to-scale models in educational applications. Overall, this literature is inconclusive on the most appropriate model specification and on the existence of returns to scale in education (see, for example, Schiltz \& De Witte, 2017 , for a recent overview). We consider the use of alternative returns to scale assumptions as scope for further research.

10. As robustness checks we have redone the analysis for alternative selections of inputs and outputs: 
excluding the variable "time devoted to math exercises" from the resources as this variable shows a large variation and a wide spread between the minimum and maximum values; dropping the school average on the math exercises as output given the large difference among schools on this variable; adding a (positively oriented) score for inequality in abilities among the students as output by using the inverse of the standard deviation of the exercise scores. This shows that our above results are quite robust. This carries over to the qualitative conclusions that we draw from them, also regarding school characteristics that relate to unexploited production capacity or resource constraints hampering the schools' performance (see below). The results are available upon request.

11. We do not report these analyses for compactness, but the results are available upon request.

\section{Acknowledgements}

We are grateful to participants of the 2015 EWEPA conference in Helsinki, the Economics in Education Workshop at Maastricht University, Efficiency in Education workshop in London, VII EFIUCO at Universidad de Córdoba, Seminar participants at University of Lille, Knox Lovell, Ernest Reig, Hervé Leleu, and Finn Førsund for useful comments.

\section{Disclosure statement}

No potential conflict of interest was reported by the author(s).

\section{Funding}

Laurens Cherchye gratefully acknowledges the European Research Council (ERC) for his Consolidator Grant 614221. Kristof De Witte acknowledges financial support from the Horizon 2020 program through the EDEN project (Economics of Education Network).

\section{ORCID}

Kristof De Witte (D) http://orcid.org/0000-0001-8230-9519

\section{References}

Afriat, S. (1972). Efficiency estimation of production functions. International Economic Review, 13(3), 568-598.

Bădin, L., Daraio, C., \& Simar, L. (2010). Optimal bandwidth selection for conditional efficiency measures: A data-driven approach. European Journal of Operational Research, 201(2), 633-640.

Banker, R. D., Charnes, R. F., \& Cooper, W. W. (1984). Some models for estimating technical and scale inefficiencies in data envelopment analysis. Management Science, 30(9), 1078-1092.

Banker, R. D., \& Morey, R. C. (1986). Efficiency analysis for exogeneously fixed inputs and outputs. Operations Research, 34(4), 513-521.
Cazals, C., Florens, J. P., \& Simar, L. (2002). Nonparametric frontier estimation: A robust approach. Journal of Econometrics, 106(1), 1-25.

Charnes, A., Cooper, W. W., \& Rhodes, E. (1978). Measuring the efficiency of decision making units. European Journal of Operational Research, 2(6), 429-444.

Cherchye, L., Moesen, W., Rogge, N., \& Van Puyenbroeck, T. (2007). An introduction to benefit of the doubt'composite indicators. Social Indicators Research, 82(1), 111-145.

Collier, T., Johnson, A., \& Ruggiero, J. (2011). Technical efficiency estimation with multiple inputs and multiple outputs using regression analysis. European Journal of Operational Research, 208(2), 153-160.

Commissie Meijerink. (2008). Over de drempels met taal en rekenen - Hoofdrapport van de expertgroep doorlopende leerlijnen taal en rekenen. Enschede, Netherlands: SLO.

Daraio, C., \& Simar, L. (2005). Introducing environmental variables in nonparametric Frontier models: A probabilistic approach. Journal of Productivity Analysis, 24(1), 93-121.

Daraio, C., \& Simar, L. (2007). Conditional nonparametric frontier models for convex and nonconvex technologies: A unifying approach. Journal of Productivity Analysis, 28(1-2), 13-32.

Estache, A., \& Wren-Lewis, L. (2009). Toward a theory of regulation for developing countries: Following JeanJacques Laffont's lead. Journal of Economic Literature, 47(3), 729-770.

Førsund, F. R. (2017). Measuring effectiveness of production in the public sector. Omega, 73, 93-103.

Fried, H. O., Lovell, C. K. \& Schmidt, S. S. (Eds.). (2008). The measurement of productive efficiency and productivity growth. Oxford, UK: Oxford University Press.

Grifel-Tatjé, E., \& Lovell, C. K. (2015). Productivity accounting: The economics of business performance. Cambridge, UK: Cambridge University Press.

Hanushek, E. A. (1995). Education production functions. In S. Durlauf \& L. Blume (Eds.), The new palgrave dictionary of economics (pp. 277-282). London: Palgrave Macmillan.

Koenker, R., \& Bassett, G., Jr. (1978). Regression quantiles. Econometrica, 46(1), 33-50.

Koopmans, T. C. (1951). An analysis of production as an efficient combination of activities. In T. C. Koopmans (Ed.), Activity analysis of production and allocation (pp. 33-97; Cowles Commission, Monograph 13). New York, NY: Wiley.

Kuosmanen, T., \& Johnson, A. L. (2017). Modeling joint production of multiple outputs in StoNED: Directional distance function approach. European Journal of Operational Research, 262(2), 792-801.

Kuosmanen, T., \& Kortelainen, M. (2012). Stochastic non-smooth envelopment of data: Semiparametric Frontier estimation subject to shape constraints. Journal of Productivity Analysis, 38(1), 11-28.

Lefebvre, M., Perelman, S., \& Pestieau, P. (2017). Productivity and performance in the public sector. In E. Grifell-Tatjé, C. A. K. Lovell, \& R. C. Sickles (Eds.), The Oxford handbook of productivity analysis. Oxford, UK: Oxford University Press.

Li, Q., \& Racine, J. S. (2007). Nonparametric econometrics: Theory and practice. Princeton, NJ: Princeton University Press. 
Lovell, C. K., \& Pastor, J. T. (1999). Radial DEA models without inputs or without outputs. European Journal of Operational Research, 118(1), 46-51.

Lovell, C. A. K., Pastor, J. T., \& Turner, J. A. (1995). Measuring macroeconomic performance in the OECD: A comparison of European and Non-European countries. European Journal of Operational Research, 87(3), 507-518.

Mbuvi, D., De Witte, K., \& Perelman, S. (2012). Urban water sector performance in Africa: A step-wise biascorrected efficiency and effectiveness analysis. Utilities Policy, 22, 31-40.

Pestieau, P. (2009). Assessing the performance of the public sector. Annals of Public and Cooperative Economics, 80(1), 133-161.

Ruggiero, J. (1996). On the measurement of technical efficiency in the public sector. European Journal of Operational Research, 90(3), 553-565.

Schiltz, F., \& De Witte, K. (2017). Estimating scale economies and the optimal size of school districts: A flexible form approach. British Educational Research Journal, 43(6), 1048-1067.

Varian, H. R. (1984). The non-parametric approach to production analysis. Econometrica, 52(3), 579-598.

Witte, D. K., \& Geys, R. (2013). Citizen coproduction and efficient public good provision: Theory and evidence from local public libraries. European Journal of Operational Research, 224(3), 592-502.

Witte, D. K., Geys, B., \& Solondz, C. (2014). Public expenditures, educational outcomes and grade inflation: Theory and evidence from a policy intervention in the Netherlands. Economics of Education Review, 40, 152-166.
Witte, D. K., Haelermans, C., \& Rogge, N. (2015). The effectiveness of a computer-assisted math learning program. Journal of Computer Assisted Learning, 31 (4), 314-329.

Witte, D. K., \& Lopez-Torres, L. (2017). Efficiency in education. A review of literature and a way forward. Journal of the Operational Research Society, 68 (4), 339-363.

Witte, D. K., \& Kortelainen, M. (2013). What explains the performance of students in a heterogeneous environment? Conditional efficiency estimation with continuous and discrete environmental variables. Applied Economics, 45(17), 2401-2412.

\section{Appendix 1}

As indicated in Section 3, the parameter $m$ in our order$m$ estimation method serves as a trimming parameter that can tune the percentage of super-efficient DMUs (i.e., DMUs with $\widehat{\operatorname{Perd}}_{E, m}>1$ for our productivity measure and with $\widehat{\operatorname{Perf}}_{E, m}>1$ for our performance measure). We follow Daraio and Simar (2005) to define the value of $m$. In particular, we systematically increase $m$ and fix it at the value for which the marginal decrease in the fraction of superefficient DMUs becomes sufficiently small. Figure A1 presents the percentage of super-efficient DMUs as a function of $m$. For low values of $m$, the percentage of super-efficient observations decreases dramatically, while this percentage decreases at a substantially slower rate when $m$ becomes larger. In our application, we selected $m=100$ because the marginal decrease in the fraction of super-efficient observations becomes very small from this point onwards.

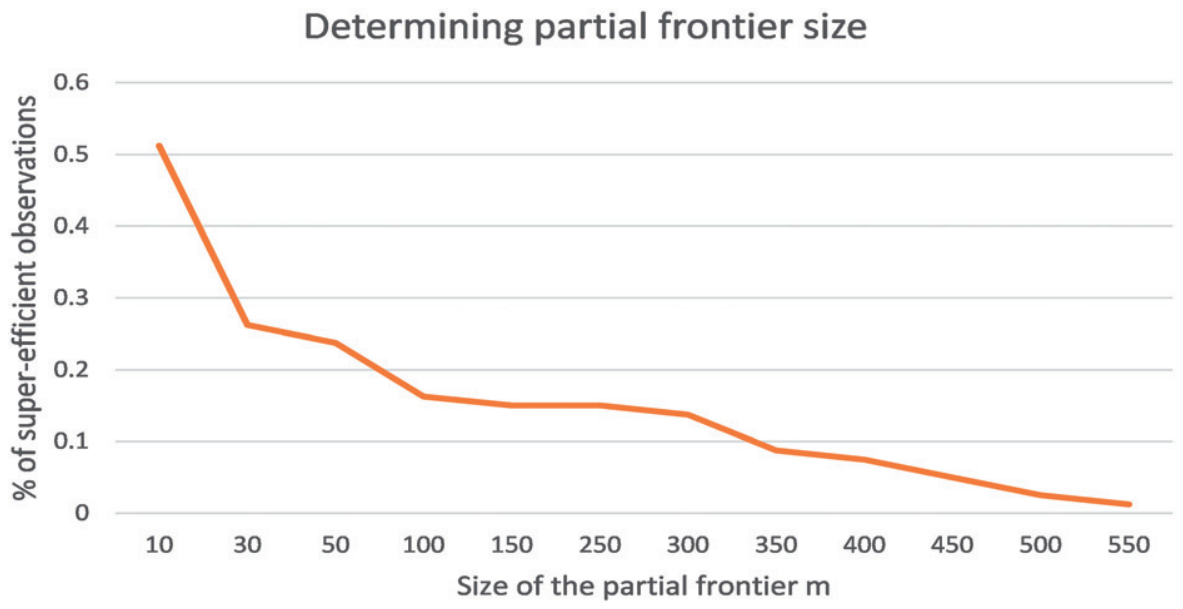

Figure A1. Determining partial frontier size. 